\title{
Modeling issues in applied efficiency analysis: agriculture
}

\author{
Giannis Karagiannis* \\ Department of Economics, University of Macedonia, Greece
}

Received: 3 February 2014

Revised: 10 March 2014

Accepted: 17 March 2014

\begin{abstract}
We provide a critical overview of the main modeling issues surrounding technical efficiency measurement in agriculture. These issues are related to the choice of orientation, the method of estimation, the modeling of "environmental factors" in both measuring and explaining efficiency, and the special treatment required for particular inputs.
\end{abstract}

Keywords: agriculture, technical efficiency, modeling issues

JEL Classification Codes: D24, Q12, Q16

\section{Introduction}

Efficiency analysis in agriculture has as long a history as the concept of efficiency per se: recall that when Farrell (1957) introduced technical and allocative efficiency in the literature he used farm data to provide the first quantitative performance assessment. Since then there has been a large and still growing number of empirical studies in agriculture. ${ }^{1}$ The results of these studies are summarized in several review papers, e.g. Ali and Byerlee (1991), Battese (1992), Bravo-Ureta and Pinheiro (1993), and Coelli (1995) as well as in the more recent meta-regression analysis studies of Thiam et al. (2001) and Bravo-Ureta et al. (2007).

Efficiency analysis in agriculture is also related to the "poor but efficient" hypothesis put forward by T.W. Schultz (1964) for traditional agricultural communities. To examine the efficiency with which farmers in traditional agriculture allocate factor inputs at their disposal, Schultz (1964) postulated that there are indeed comparatively few significant inefficiencies in the allocative behavior of traditional farmers. The "poor but efficient" hypothesis is mainly related to allocative efficiency and this part of the literature will not be a subject of our proceeding discussion.

\footnotetext{
*E-mail: karagian@uom.gr.

Citation: Karagiannis, G. (2014) Modeling issues in applied efficiency analysis: agriculture, Economics and Business Letters, 3(1), 12-18.

${ }^{1}$ Agriculture is, along with banking, hospitals and education, one of the sectors with the largest number of efficiency measurement applications.
} 
In this letter I attempt to summarize the main modeling issues surrounding technical efficiency measurement in agriculture. They will refer to the choice of orientation, the method of estimation, the modeling of "environmental factors" in both measuring and explaining efficiency, the special treatment required for particular inputs such as extension services and pesticides, and last but not least the form of the production frontier itself.

\section{Specification issues}

In most (if not all) of the existing empirical studies in agriculture, technical efficiency is measured in an output-oriented manner: that is, it gives the maximum amount by which output(s) can increase for a given production technology and the observed input use. The choice of the output-oriented measure is more appropriate in the case of agriculture as farmers have mainly control over decisions regarding input use and not output(s), which are subject to several uncontrollable factors including weather conditions, pest, and diseases.

As these uncontrolled factors are an inherent part of agricultural production and are likely to play a significant role in the level of output produced, the assumption that all deviations from the frontier are due to inefficiency seems to be invalid and an explicit separation of inefficiency from stochastic noise is in order. This in turn suggests that stochastic rather than deterministic types of frontier models are more appropriate for assessing performance evaluation in agriculture. Without accounting for stochastic noise, technical efficiency will be overestimated under favorable conditions (i.e., in "good years") and underestimated under unfavorable conditions (i.e., "bad years"). Thus I would suggest that in most cases (perhaps with the exception of greenhouse production) the stochastic frontier approach, which explicitly separates statistical noise from technical efficiency, should be the appropriate modeling choice for agriculture. ${ }^{2}$

From the stochastic frontier models those that I think fit better with agriculture is the set of random effect models, which assume no correlation between the regressors (i.e., input quantities) and the composite error term including the inefficiency term. The reason is as follows: since both output prices and quantities are rarely known with certainty when farmers make their production decisions, it seems reasonable to consider that expected rather actual profit maximization is the underlying behavioral assumption (Coelli, 1995). In addition, the choice of inputs to maximize expected profit is assumed to be subject to human errors that are however uncorrelated with statistical noise. Since production takes a substantial amount of time to be completed, we can argue that the correlation between the largely weather-affected stochastic error term and the largely predetermined input variables is zero or very small (Griliches, 1963). In addition, in this case the single-equation estimation of the production frontier function, as in stochastic frontier models, does not suffer from simultaneous equations bias (Zellner, Kmenta and Dreze, 1966).

On the other hand, as agriculture is a sector in which producers do not have considerable control over the physical production environment, a set of variables related to soil quality, altitude and other location and geographical characteristics are usually included in the analysis to account for geoclimatic heterogeneity. As these "environmental" factors are assumed to influence the production process directly and not the efficiency by which inputs are utilized, they are included into the production frontier and not in the inefficiency effect function (if such a function is included in model specification). Given the nature of these

\footnotetext{
${ }^{2}$ For greenhouse production weather conditions have a negligible (if any) impact on output produced while it is expected that the other uncontrolled factors, such as pests and diseases, would have a definitely smaller impact compared to crop or perennial production. As a result, not accounting for stochastic noise, and employing instead deterministic type of frontier models, will not have a great impact on the estimated technical efficiency.
} 
environmental variables it is then reasonable to assume that they enter into the production frontier in an additive and separable way, which implies that their impact on output is independent of inputs. Thus they have a neutral impact on the production frontier by modifying its intercept term. Sherlund, Barrett and Adesima (2002) showed that neglecting heterogeneity in the physical production environment leads to significantly inflated estimates of technical inefficiency.

Nevertheless, other models assuming heterogeneity in both the intercept and in the slope parameters of the production frontier are less appropriate for the agriculture. From this class of technology heterogeneity frontier models, the latent class models are suitable for application dealing with performance assessment between different farming practices, as for example conventional and organic farming or intensive and extensive enterprises (e.g., Alvarez and Corral, 2010). In contrast, random coefficient models are not appropriate as for most crops and livestock products there is a very well-known, no-surprises (as in the case IT industry) production technology.

\section{Issues related to specific inputs}

A number of other modelling issues are directly related to agricultural inputs. First, in many cases we have to deal with zero-values of input and/or output variables. For example, quantity data on agricultural inputs in developing countries frequently have zero values for chemical fertilizers and pesticides -at least for a subset of farmers- and similarly for hired labor in developed countries, while for extension services this may be true for both developed and developing countries. In these cases, confining the analysis only to those farmers with nonzero entries for all inputs considered may not be the most appropriate approach as the information contained in the data of farmers with some zero-value inputs may be useful in the estimation of the other technology parameters. Battese (1997) suggested a way to overcome this problem and use the complete data set: include a dummy variable (taking the value one when a zero-value input is reported) among the regressors and for the quantity of the input with zero entries use the max of the actual quantity reported and one. For an extension to multi-output technologies with zero-value output entries see Tsekouras, Pantzios and Karagiannis (2004).

Second, another modelling peculiarity is that inputs such as pesticides and veterinary services have no output-expanding impact but rather prevent output from harmful pest attacks and diseases. Such damage control inputs have only an indirect impact on output and thus should not be treated symmetrically with other output expanding inputs. Realizing that the marginal productivity of pesticides reflects their ability to reduce crop damage due to pest infestation and not to increase output directly implies that abatement rather than pesticides enters directly into the production frontier function. Abatement is thus treated as an intermediate product of pesticides and it is described by means of a damage or control function, which usually has an exponential specification. Karagiannis and Tzouvelekas (2011) incorporated this into a stochastic frontier model, the estimation of which is greatly facilitated by applying a grid search procedure into conventional MLE.

Third, some of the inputs used in the production process may also be responsible for using a particular technology more successfully. This may occur when farmers have acquired more information, knowledge and experience with respect to one input's productivity than another, or some inputs indirectly affect the productivity of other inputs (Dinar, Karagiannis and Tzouvelekas, 2007). Extension visits and fertilizer and water in the production of high yield varieties fulfil both of these requirements. In terms of modelling strategy this points to the use of the non-neutral stochastic frontier model, proposed by Huang and Liu (1994), which assumes that technical efficiency depends on both the method of applications of inputs and 
the intensity of some inputs use. In the case of livestock, Karagiannis and Tzouvelekas (2005) found that flock size and feeding have such dual roles in affecting both production and the efficiency with which resources are converted into output(s).

\section{Other modelling issues}

The last but one modelling issue that I would like to discuss here concerns the explanation of (technical) efficiency differences. This is a common practice in many performance evaluation studies and agriculture is not an exception. The difference is however that, in many cases, the monotonic formulation of the so called inefficiency effect model (e.g. Batesse and Coelli, 1995) commonly used in stochastic frontier analysis cannot be used to accurately examine non-monotonic relationships that in some instances appear in agriculture. Such nonmonotonic relationships have been found between efficiency and for example farmer's age, farm size, and subsidies in the sense that these explanatory variables may have a positive impact on technical efficiency at their low values but a negative impact at high values, or vice versa. If such cases are expected to emerge in particular cases it is convenient to use from the outset the non-monotonic inefficiency effect model, proposed by Wang (2002), that allows for both formal statistical testing and analysis of non-monotonic relations.

Regarding the impact of farmer's age on efficiency, it may be argued that efficiency increases with age in the early years of a farmer's life but it decreases with age in the later years. That is, the productive efficiency of a young farmer improves as he matures and accumulates experiences but an old farmer will more likely suffer efficiency losses due to deteriorated mental and physical capacity. In addition, younger farmers become more efficient as they are more aware of current technology and tend to more easily acquire knowledge about technical advantages. According to empirical results by Wang (2002) on a sample of Indian farmers, the turning point is likely to take place between the age of 50 and 60 .

The relationship between farm size and efficiency, on the other hand, has a long history in agriculture and still remains a debatable issue: see Alvarez and Arias (2004) for a survey. It has been argued that larger farms, by exploiting scale economies, tend to be more efficient than small farms (Hallam and Machado, 1996) but due to their size larger farms may also have difficulties in conducting their operation at the optimal time and thus use their inputs less efficiently (Amara et al., 1999). In addition, a U-shaped relationship has been found between size and efficiency where efficiency falls initially as farm size increases but beyond a particular size it starts to rise again (Helfand and Levine, 2004). The empirical findings vary by the method of estimating efficiency as well as the method used for explaining efficiency differences (one- or two-step procedure). If the one-step procedure is used, which by the way is the theoretically appropriate approach, the size variable included in the inefficiency effect function must not be measured in terms of the dependent variable (i.e., the observed output); it is better to measure size in terms of inputs, such as land or herd size, not outputs (Wang and Schmidt, 2002).

The role of farm subsidies in efficiency studies is much more debatable: they have occasionally been modelled as inputs or outputs but it is my impression that they should be included in the inefficiency effect function as far as estimation of technical efficiency is concerned. The impact of farm subsidies on technical efficiency may be positive or negative: if they are used to improve the know-how of existing technology they may have a positive impact but they may also make farmers more complacent about their production and hence less efficient. Nevertheless, subsidies may have a positive impact on technical efficiency at low values of farm subsidies and a negative impact for high values, as was hypothesized by Zhu, Karagiannis and Oude Lansink (2011). They used the non-monotonic technical 
inefficiency effect model that allows for formally testing whether a monotonic or a nonmonotonic relationship exists between technical efficiency and farm subsidies.

\section{Modelling issues with other types of technical efficiency}

Last but not least I would like to mention that in many agricultural efficiency studies we are also interested in other types of efficiency apart from technical efficiency. These usually refer to scale and input-specific efficiency. The relation between farm size and efficiency is still a timely research and policy question in agriculture economics where the role of optimal scale size and scale efficiency is pivotal (e.g., Karagiannis and Sarrris, 2005). On the other hand, in several studies we are particularly interested in examining the extent of efficient use of specific inputs, such as irrigation water (Karagiannis, Tzouvelekas and Xepapadeas, 2003) or fertilizer (Reinhard, Lovell and Thijssen, 1999). Scale and input-specific efficiencies can be computed directly from the estimated stochastic frontier model ${ }^{3}$ and it is also theoretically consistent to use a second stage regression to explain differences across producers. ${ }^{4}$ They thus provide useful information that can be obtained without additional estimation effort and can be readily explored by the researchers as long as a flexible functional form such as the translog is used. Notice that the restricted nature of the Cobb-Douglas does not offer such an option. It is well known that the flexible functional forms have additional advantages as they allow for variable returns to scales and substitution elasticities, among others.

\section{Concluding remarks}

We have provided a critical overview of the main modeling issues surrounding technical efficiency measurement in agriculture, which are related to the choice of orientation, the method of estimation, the modeling of "environmental factors" in both measuring and explaining efficiency, and the special treatment required for particular inputs. Besides these, future research has to explicitly consider the role of production uncertainty and the riskincreasing (e.g., fertilizer) and risk-reducing (e.g., family labor, water) nature of agricultural inputs. In addition, more effort should be placed in modeling and accurately measuring environmental efficiency in agriculture, as here inputs rather than outputs are usually the sources of externalities.

\section{References}

Ali, M. and Byerlee, D. (1991) Economic efficiency of small farmers in a changing world: a survey of recent evidence, Journal of International Development, 3, 1-27.

Alvarez, A. and Arias, C. (2004) Technical efficiency and farm size: a conditional analysis, Agricultural Economics, 30, 241-250.

Alvarez, A. and del Corral, J. (2010) Identifying different technologies using a latent class model: extensive versus intensive dairy farms, European Review of Agricultural Economics, 37, 231-250.

\footnotetext{
${ }^{3}$ Ray (1998) and Reinhard, Lovell and Thijssen (1999) explained the detailed derivation of scale and inputspecific efficiencies respectively from the estimated (technology and efficiency distribution) parameters of a flexible frontier function, such as the translog.

${ }^{4}$ Reinhard, Lovell and Thijssen (1999) argued that the two-stage approach can be used without any further complications as long as the efficiency scores involved in the second stage regression are calculated from the first-stage parameter estimates instead of being directly estimated econometrically at the first stage. This holds for both scale and input-specific efficiencies.
} 
Amara, N., Traore, N., Landry, R., and Romain, R. (1999) Technical efficiency and farmer's attitudes toward technological innovations: the case of the potato farmers in Quebec, Canadian Journal of Agricultural Economics, 47, 31-43.

Battese, G.E. (1992) Frontier production functions and technical efficiency: a survey of empirical applications in Agricultural Economics, Agricultural Economics, 7, 185208.

Battese, G.E. (1997) A note on the estimation of Cobb-Douglas production functions when some explanatory variables have zero values, Journal of Agricultural Economics, 48, 250-252.

Battese, G.E. and Coelli, T.J. (1995) A model for technical inefficiency effects in a stochastic frontier production function for panel data, Empirical Economics, 20, 325-332.

Bravo-Ureta, B.E. and Pinheiro, A.E. (1993) Efficiency analysis of developing country agriculture: a review of frontier function literature, Agricultural and Resource Economics Review, 22, 88-101.

Bravo-Ureta, B.E., Solis, D., Lopez, V.H.M., Maripani, J.F., Thiam, A. and Rivas, T. (2007) Technical efficiency in farming: a meta-regression analysis, Journal of Productivity Analysis, 27, 57-72.

Coelli, T.J. (1995) Recent developments in frontier modeling and efficiency measurement, Australian Journal of Agricultural Economics, 39, 219-245.

Dinar, A., Karagiannis, G. and Tzouvelekas, V. (2007) Evaluating the impact of agricultural extension on farms' performance in Crete: a nonneutral stochastic frontier approach, Agricultural Economics, 36, 135-146.

Farrell, M.J. (1957) The measurement of productive efficiency, Journal of Royal Statistical Society Series A, 120, 253-281.

Griliches, Z. (1963) Estimation of the aggregate production function from cross sectional data, Journal Farm Economics, 45, 419-428.

Hallam, D. and Machado, F. (1996) Efficiency analysis with panel data: a study of Portuguese dairy farms, European Review of Agricultural Economics, 23, 79-93.

Helfand, S.V. and Levine, E.S. (2004) Farm size and the determinants of productive efficiency in Brazilian center-west, Agricultural Economics, 31, 241-249.

Huang, C.J. and Liu, J.T. (1994) Estimation of a non-neutral stochastic frontier production function, Journal of Productivity Analysis, 5, 171-180.

Karagiannis, G. and Sarris, A. (2005) Measuring and explaining scale efficiency with the parametric approach: the case of Greek tobacco growers, Agricultural Economics, 33, 441-451.

Karagiannis, G. and Tzouvelekas, V. (2005) Explaining output growth with a heteroscedastic non-neutral production frontier: the case of sheep farms in Greece, European Review of Agricultural Economics, 32, 51-74.

Karagiannis, G. and Tzouvelekas, V. (2012) The damage-control effect of pesticides on total factor productivity growth, European Review of Agricultural Economics, 39, 417-437.

Karagiannis, G., Tzouvelekas, V. and Xepapadeas, A. (2003) Measuring irrigation water efficiency with a stochastic production frontier, Environmental and Resource Economics, 26, 57-72.

Ray, S.C. (1998) Measuring scale efficiency from a translog production function, Journal of Productivity Analysis, 11, 183-194.

Reinhard, S., Lovell, C.A.K. and Thijssen, G.J. (1999) Econometric estimation of technical and environmental efficiency: an application to Dutch dairy farms, American Journal of Agricultural Economics, 81, 44-60.

Schultz, T.W. (1964) Transforming traditional agriculture, University of Chicago Press. 
Sherlund, S.M., Barrett, C.B. and Adesima, A.A. (2002) Smallholder technical efficiency controlling for environmental production conditions, Journal of Development Economics, 69, 85-101.

Thiam, A., Bravo-Ureta, B.E. and Rivas, T. (2001) Technical efficiency in developing agriculture: a meta-analysis, Agricultural Economics, 25, 235-243.

Tsekouras, K.D., Pantzios, C.J. and Karagiannis, G. (2004) Malmquist productivity index estimation with zero-value variables: the case of Greek prefectural training councils, International Journal of Production Economics, 89, 95-106.

Wang, H.J. (2002) Heteroscedasticity and non-monotonic efficiency effects of a stochastic frontier model, Journal of Productivity Analysis, 18, 241-253.

Wang, H.J. and Schmidt, P. (2002) One-step and two-step estimation of the effects of exogenous variables on technical efficiency levels, Journal of Productivity Analysis, 18, 129-144.

Zellner, A., Kmenta, J. and Dreze, J. (1966) Specification and estimation of Cobb-Douglas production function models, Econometrica, 34, 784-795.

Zhu, X., Karagiannis, G. and Oude Lansink, A. (2011) The impact of direct income transfers of CAP on Greek olive farms' performance: using a non-monotonic inefficiency effects model, Journal of Agricultural Economics, 62, 630-638. 